\title{
PARTIAL PREGOPULATORY ISOLATION BETWEEN TWO GEOGRAPHIGALLY DISTANT POPULATIONS OF THE LAND SNAIL ARIANTA ARBUSTORUM (L.)
}

\author{
SANDRA KUPFERNAGEL AND BRUNO BAUR \\ Section of Conservation Biology, Department of Environmental Sciences, University of Basel, St Johanns-Vorstadt 10, CH-4056 Basel, Switzerland \\ Correspondence: S. Kupfernagel; e-mail: sandra.kupfernagel@unibas.ch
}

(Received 19 May 2010; accepted 1 October 2010)

\begin{abstract}
Different mechanisms of reproductive isolation were examined in the simultaneously hermaphroditic land snail Arianta arbustorum. Snails from two geographically isolated populations in the Swiss Alps were allowed to copulate with both a homotypic (individual from the same population) and a heterotypic (individual from the other population) partner (in half of the pairs in reversed order). Control snails mated twice with a homotypic partner. In the first mating, successful copulations occurred in a lower frequency in heterotypic pairs $(55.6 \%)$ than in homotypic pairs $(82.9 \%)$. Heterotypic pairs that eventually copulated showed more breaks during courtship than homotypic pairs. However, neither the number of eggs produced nor their hatching success was influenced by the type of mating partner. In the second mating, the sequence of different partners had an effect on the proportion of successful copulations in snails from one geographical population. Snails that copulated first with a homotypic partner remated more frequently with a homotypic partner than snails that copulated first with a heterotypic partner. Paternity analyses of progeny of snails that mated twice indicate no influence of the origin of the mating partner. The proportion of hatchlings sired by the second mate $\left(P_{2}\right)$ averaged 0.39 , indicating a slight first-mate advantage. However, highly skewed paternity patterns were found in the progeny of $44.4 \%$ of the double-mated snails. Genetic analyses also revealed a low frequency of self-fertilization $(3.7 \%)$. These findings indicate the presence of partial precopulatory isolation between two distant snail populations, although reproductive compatibility is still maintained.
\end{abstract}

\section{INTRODUCTION}

Reproductive isolation is an important step in the process of speciation. In animals, reproductive isolation mechanisms can appear before or after copulation and are therefore divided into precopulatory and postcopulatory isolation mechanisms (Mayr, 1963). Reproductive barriers can take various forms and can be established in different ways, for example, by geographical separation of small populations or changes in behavioural patterns (Coyne \& Orr, 2004; Rundle \& Nosil, 2005). Such shifts seldom evolve spontaneously, but often gradually over generations (Barton \& Charlesworth, 1984).

The occurrence of reproductive isolation mechanisms between natural populations has an important impact on the reduction of gene flow and can therefore influence the genetic diversity and fitness of populations. Moreover, inbreeding, i.e. mating between close relatives and, in hermaphrodites, selffertilization (Jarne \& Auld, 2006), and outbreeding, i.e. reproduction between unrelated individuals from different populations (heterotypic), influence genetic diversity and fitness in natural populations (Frankham, 1995).

In recent years, the impact of inbreeding has been investigated extensively in gonochoristic (species with separate sexes) and in hermaphroditic animals. In contrast, the effects of outbreeding have been given little attention, especially in hermaphroditic animals (for an exception see McCarthy \& Sih, 2008). However, outbreeding depression, where offspring from heterotypic copulations show a reduced fitness and lower adaptation ability to prevailing conditions than offspring from local (homotypic) copulations, can be seen as one component for evolving reproductive isolation.
Hermaphroditic land snails with low dispersal ability are excellent study organisms for the examination of isolation mechanisms evolving in natural populations (Gittenberger, 1988; Baur \& Baur, 1992a; Schilthuizen et al., 2006). Different localities are characterized by different selection pressures and, with low dispersal capacity and limited gene flow, small snail populations adapt differently from locality to locality (Hanski \& Gilpin, 1997). Reproductive isolation mechanisms can arise gradually and outbreeding effects between different localities can be tested. Additionally, in populations with reduced gene flow, the selection of specific partner traits can lead to the development of population-specific partner preferences, which can increase the reproductive isolation of a population. As a result, sexual selection processes go hand-in-hand with isolation processes.

Sexual selection, in general, is divided into processes that occur before mating (precopulatory selection, e.g. courtship) and inside the female organs after the mating (postcopulatory selection). Postcopulatory sexual selection can be caused either by sperm competition between different mating partners or by cryptic female choice and selective sperm utilization (Birkhead \& Møller, 1998). In simultaneously hermaphroditic animals, precopulatory selection processes are influenced by both the female and the male traits of an individual. Greeff \& Michiels (1999) suggested that selection on traits related to mate acquisition is intrinsically weaker in hermaphrodites than in gonochorists and that the postcopulatory mechanism might be more essential. Additionally, in hermaphroditic helicid snails, longtime sperm storage from different mating partners, complex sperm storage organs and a mechanism for the digestion of 
excess sperm are known (Baur, 1998; Beese, Beier \& Baur, 2006; Beese et al., 2009) and can influence the outcome of the variation observed in sperm utilization (Haase \& Baur, 1995; Chase \& Darbyson, 2008; Kupfernagel, Rusterholz \& Baur, 2010).

In this study, we investigated precopulatory and postcopulatory isolation mechanisms that might have evolved during a long period of geographical isolation in two populations of Arianta arbustorum (L.). This simultaneously hermaphroditic land snail has a continuous distribution across northern and western Europe (Kerney \& Cameron, 1979). The dispersal of marked individuals averaged $7 \mathrm{~m}$ in 1 year (Baur, 1986) and, due to limited dispersal ability, metapopulations exist (Akçakaya \& Baur, 1996). Large differences in life-history characters have been reported between distant populations, including shell size, maturation time, egg size and clutch size (Baur, 1984, 1986, 1990; Baur \& Gosteli, 1986; Baur \& Raboud, 1988).

In hermaphrodites, the ability to reproduce by selffertilization is a means of coping with limited dispersal ability or low mate-encounter rate in low-density populations (Levins, 1968). Mixed mating systems, where reproduction occurs via self- and cross-fertilization, are common in plants (Goodwillie, Kalisz \& Eckert, 2005) and have also been found in a variety of simultaneously hermaphroditic gastropods (Baur, 1987; Heller, 1993; Jarne \& Auld, 2006). In general, complete outcrossing is preferred when the inbreeding effects are pronounced (Lande \& Schemske, 1985). In natural populations of pulmonate land snails, however, it remains unclear how frequently selfing or outcrossing occur and which mechanisms can lead to a switch in the reproduction mode (Heller, 1993; Backeljau, Baur \& Baur, 2001).

Cross-fertilization is the dominant mode of reproduction in A. arbustorum although, in the absence of a potential mating partner, self-fertilization can be observed in controlled laboratory experiments (Chen, 1994). However, snails kept isolated for $2-3$ years produced a reduced number of eggs $(1-2 \%$ of mated snails) with a decreased hatching success (Chen, 1994). In natural populations of $A$. arbustorum, genetic analyses revealed a low frequency of self-fertilizations in one population, but no selfing in three other populations (Kupfernagel et al., 2010).

The present study was designed to investigate whether selective sperm use and/or self-fertilization is involved in outbreeding avoidance, which may explain patterns of postcopulatory isolation already observed between animals from these geographically distant populations (Baur \& Baur, 1992a). Using microsatellite markers, we examined patterns of paternity in mating trials where focal snails mate with both an unrelated snail from the same population and an individual from a geographically remote population in either order. Applying genetic analyses, the mating order effect was analysed by estimating the sperm precedence and the differential sperm utilization from consecutive matings.

\section{MATERIAL AND METHODS}

\section{Study organism}

Arianta arbustorum is common in moist habitats of northwestern and central Europe (Kerney \& Cameron, 1979). The snail has determinate growth (shell breadth of adults $17-22 \mathrm{~mm}$ ). Individuals become sexually mature at 2-4 years and adults live another 3-4 years (Baur \& Raboud, 1988). Mating is random with respect to shell size and different degrees of relatedness (Baur, 1992; Baur \& Baur, 1997). Mating behaviour in A. arbustorum includes elaborate courtship behaviour, which consists of introductory behaviour (foreplay) with reciprocal tactile and oral contacts, and curving turns to reach an optimal position with respect to the genital opening of the partner (Hofmann, 1923; B.B., unpubl.). This is followed by an optional dart shooting, the pushing of a calcareous dart into the mating partner's body, which is assumed to increase sperm storage in the partner (Rogers \& Chase, 2001; Chase 2007). Copulation is reciprocal; both snails simultaneously transfer one spermatophore. The mating process lasts $2-18 \mathrm{~h}$ (Baur \& Baur, 1992b). After a successful copulation, individuals need at least 8 days to replenish their sperm reserves (Locher \& Baur, 1999; Hänggi, Locher \& Baur, 2002). Arianta arbustorum mates repeatedly in the course of a reproductive season and fertile sperm can be stored for more than 1 year in the sperm storage organ (Baur, 1988). In the field, snails deposit 1-3 egg batches consisting of 20-50 eggs per year (Baur, 1990). A controlled laboratory experiment showed that one successful copulation per reproductive season is sufficient to fertilize all the eggs produced by one individual (Chen \& Baur, 1993). There is, however, a probability of $5-8 \%$ that a copulation does not lead to fertilization of eggs, due to lack of sperm transfer, transfer of infertile sperm or sperm digestion (Chen \& Baur, 1993).

\section{Snail samples}

Virgin individuals (subadult snails that had not yet completed shell growth) of $A$. arbustorum were collected in spring 2007 and 2008 from two different sites in the Swiss Alps: in Gantrisch, an alpine pasture $30 \mathrm{~km}$ south of Berne $\left(46^{\circ} 42^{\prime} \mathrm{N}, 7^{\circ} 27^{\prime} \mathrm{E}\right.$, elevation $1810 \mathrm{~m}$ a.s.l.; hereafter referred to as $\mathrm{G}$ ) and Strela, an alpine pasture with scattered scree $4 \mathrm{~km}$ west of Davos $\left(46^{\circ} 49^{\prime} \mathrm{N}, 9^{\circ} 48^{\prime} \mathrm{E}\right.$, elevation $2100 \mathrm{~m}$ a.s.l.; referred to as $\left.\mathrm{S}\right)$. The sites are situated $180 \mathrm{~km}$ apart.

The snails were kept individually in transparent beakers (8 cm deep, $6.5 \mathrm{~cm}$ diameter) lined with moist soil $(c .4 \mathrm{~cm})$ at $19^{\circ} \mathrm{C}$ with a light:dark cycle of $16: 8 \mathrm{~h}$ until they reached sexual maturity as indicated by the formation of a reflected lip at the shell aperture. Fresh lettuce was provided twice a week and at the same time the beakers were cleaned. The snails were marked individually by writing numbers on their shells with a waterproof felt-tipped pen on a spot of correction fluid (Tipp-Ex). The animals showed no visible reaction to the marking procedure.

\section{Mating experiment}

The cross-mating experiment was conducted to examine whether premating and/or postmating isolation occurs between individuals from the two distant populations. Prior to mating, sexually mature snails were genotyped using a noninvasive method (see below). Virgin individuals (focal snails) from both populations were mated twice: first with a virgin snail from the same population (homotypic matings) and second with another virgin snail from a distant population (heterotypic matings). In half of the snails the mating order was reversed (Table 1). As a control, focal snails were mated with two virgin partners from the same population. Partners of homotypic matings were not related to each other.

Mating trials were initiated in the evening and run during the night (with natural temperature fluctuation) in the summers of 2007 and 2008, respectively. This period is the time of maximum mating activity in natural snail populations (Cain \& Currey, 1968; Wolda \& Kreulen, 1973). The focal snail and a randomly chosen sperm donor which, however, differed from the focal snail in at least two highly variable microsatellite primers (see below), were placed in a transparent beaker (measuring $14 \times 10 \times 7 \mathrm{~cm}$ ) whose bottom was covered with moistened paper towelling to maintain snail activity. The snails' behaviour was monitored using spot checks at intervals of 20 min from 8 p.m. to 6 a.m. (at night using a flash light). 
Table 1. Design of the mating experiment with focal snails of Arianta arbustorum that mated twice and type of data collected.

\begin{tabular}{|c|c|c|c|c|c|}
\hline \multirow{3}{*}{$\begin{array}{l}\text { Focal snail (population) } \\
\mathrm{G}\end{array}$} & \multicolumn{4}{|c|}{ Mating sequence } & \multirow{3}{*}{$\begin{array}{l}\text { Mating group* } \\
\text { Foc. } \times \text { Homot. } \times \text { Heterot. }\end{array}$} \\
\hline & \multicolumn{2}{|c|}{ First mating partner } & \multicolumn{2}{|c|}{ Second mating partner } & \\
\hline & $\mathrm{G}$ & $\mathrm{a}, \mathrm{b}, \mathrm{c},-,-$ & $s$ & $\mathrm{a}, \mathrm{b},-, \mathrm{d}, \mathrm{e}$ & \\
\hline $\mathrm{G}$ & $S$ & $a, b, c,-, e$ & $\mathrm{G}$ & $a, b,-, d, e$ & Foc. $\times$ Heterot. $\times$ Homot. \\
\hline$G$ & $G$ & $a, b, c,-,-$ & $G$ & $a, b,-, d, e$ & Foc. $\times$ Homot. $\times$ Homot. (control) \\
\hline $\mathrm{s}$ & $\mathrm{s}$ & $a, b, c,-,-$ & $G$ & $a, b,-,-,-$ & Foc. $\times$ Homot. $\times$ Heterot. \\
\hline $\mathrm{s}$ & $G$ & $a, b, c,-, e$ & $\mathrm{~s}$ & $a, b,-, d, e$ & Foc. $\times$ Heterot. $\times$ Homot. \\
\hline$S$ & $S$ & $a, b, c,-,-$ & $\mathrm{S}$ & $a, b,-,-,-$ & Foc. $\times$ Homot. $\times$ Homot. (control) \\
\hline
\end{tabular}

Focal snails from two populations (G, Gantrisch; S, Strela) copulated with homotypic or heterotypic partners in different order. Type of data: (a) frequency of successful copulations; (b) mating behaviour; (c) number of eggs produced between first and second copulation; (d) number of eggs produced after second copulation; (e) paternity analysis of offspring.

${ }^{*}$ In both populations the sequence with two heterotypic partners (Foc. $\times$ Heterot. $\times$ Heterot.) was not considered.

We recorded the following behaviour: (1) active but no courtship; (2) introductory courtship behaviour, contact between mating partners; (3) progressed courtship, curving turns with swollen genitals; (4) body contact, attempted copulation; and (5) copulation. Records included time until initiation of courtship (courtship latency), courtship duration (time interval from courtship initiation to copulation) and copulation duration. The initiation of courtship was defined as the first simultaneous oral contact (which was usually accompanied by a slight eversion of the penial lobe in at least one of the snails) and the beginning of the copulation as the first simultaneous intromission. Furthermore, we recorded the number and duration of behavioural discontinuities (breaks in mating behaviour). Observation sessions were terminated either when two snails mated or after $10 \mathrm{~h}$ if no snail initiated courtship behaviour. Between mating trials, snails were maintained as described above.

After the first copulation, all focal snails were allowed to replenish their autosperm reserves for 7 days (Locher \& Baur, 1999). Then, they were allowed to copulate with a second partner following the experimental setup shown in Table 1. Behavioural records were as described in the first copulation. However, most snails did not mate at the first attempt. These individuals were placed together with another potential mate of the same group as the previous one in test boxes after 1 week or more. For each focal snail we also recorded time until first mating, time until second mating and time between second copulation and oviposition. The 106 individuals involved in the first copulation were allowed to remate with a new virgin partner (second copulation).

\section{Reproductive performance}

To examine whether individuals that copulated with a partner from a distant population show reduced reproductive performance, we examined the number of eggs and hatchlings produced by each snail. We checked beakers of focal snails for eggs once per week. The eggs of each batch were collected, counted and kept in a plastic dish $(6.5 \mathrm{~cm}$ in diameter) lined with moist paper towelling at $19^{\circ} \mathrm{C}$ to determine hatching success. Newly hatched snails were counted and separated from remaining unhatched eggs to prevent egg cannibalism (Baur, 1994b). Labelled in order of emergence, the hatchlings were stored at $-80^{\circ} \mathrm{C}$ until genetic analysis.

\section{Parental genotyping and paternity analyses}

DNA of focal snails and mating partners was obtained from foot mucus using a noninvasive technique (Armbruster, Koller
\& Baur, 2005). We screened the DNA for microsatellite repeats using at least at two highly variable primer pairs $(24,26,55$ or/and A9) developed by Armbruster et al. (2005). The same microsatellite loci were considered in paternity analyses using the tissue of hatchlings as DNA source. DNA of focal snails, mating partners and individual hatchlings was extracted following the DNeasy protocol of Qiagen (2006). PCR-mixture (HotStarTaq Mastermix Kit, Qiagen AG, Switzerland) was 4-6 ng of DNA (4.5 and $3 \mu \mathrm{l}$ per focal snail and hatchling, respectively) in a total volume of $10 \mu$ f following the protocol of Qiagen (2003). PCR-mixtures were preheated at $95^{\circ} \mathrm{C}$ for $15 \mathrm{~min}$, followed by $30-35$ cycles of $95^{\circ} \mathrm{C}$ for $30 \mathrm{~s}$, locus specific annealing for $30 \mathrm{~s}$ and $72^{\circ} \mathrm{C}$ for $30 \mathrm{~s}$ (Armbruster et al., 2005). PCR was finished with an extension of $8 \mathrm{~min}$ at $72^{\circ} \mathrm{C}$. Horizontal electrophoresis was performed with SEA2000 ${ }^{\mathrm{TM}}$ advanced submerged-gel electrophoresis equipment. Spreadex ${ }^{\circledR}$ EL400 gels (Elchrom Scientific AG, Switzerland) were used.

\section{Data analyses}

Null alleles can significantly affect estimates of genetic relatedness of individuals and population genetic structure (Pemberton et al., 1995; Dakin \& Avise, 2004). We used exclusively snails with detectable allele banding. Thus, occurrence of null alleles should be relatively low and should not have influenced parentage assignment.

As a measure for mating propensity, we used the percentage of snails mating in all trials (first copulation). For statistical analyses of courtship latency, courtship duration and copulation duration we considered only records from mating pairs. We used $\chi^{2}$-test to examine whether snails from the two populations differed in proportions of successful homotypic and heterotypic mating trials. We applied two-way ANOVAs with the factors population and mating partner to examine possible effects of the origin of the focal snail and the type of mating partner (homotypic vs heterotypic) on copulation duration and number of eggs produced (logtransformed) and hatching success of eggs (arcsintransformed). Data on time elapsed between two copulations, courtship latency, courtship duration and the proportion of hatchlings sired by the second mating partner ( $P_{2}$-value) did not fit normal distributions. Differences in these variables between homotypic and heterotypic pairs were analysed using the Kruskal-Wallis test followed by the Mann-Whitney $U$-test for group comparisons. The rate of self-fertilization was quantified using genotyped data of the offspring and their parents. All statistical analyses were conducted using SPSS $^{\circledR} 13$ (SPSS, 2006), unless otherwise noted. 


\section{RESULTS}

\section{First copulation: precopulatory mechanism}

The mating groups differed in frequency of successful copulations $\left(\chi^{2}\right.$-test: $\left.\chi^{2}=6.73, \mathrm{df}=2, P=0.035\right)$. Sixteen out of 17 $(94.1 \%) \mathrm{G} \times \mathrm{G}$ pairs and 13 of $18(72.2 \%) \mathrm{S} \times \mathrm{S}$ pairs copulated, but only 10 of the $18(55.6 \%) \mathrm{S} \times \mathrm{G}$ pairs. The heterotypic $\mathrm{S} \times \mathrm{G}$ pairs showed a lower frequency of successful matings than the homotypic pairs (both populations combined; $\left.\chi^{2}=4.56, \mathrm{df}=1, P=0.032\right)$, while the two groups of homotypic pairs did not differ in frequency of successful matings $\left(\chi^{2}=2.95, \mathrm{df}=1, P=0.09\right)$. This suggests the occurrence of a precopulatory isolation mechanism between snails from the two distant populations. Snails from the two populations showed slight but nonsignificant differences in mating propensity (population $\mathrm{G}$ : $80.8 \%$, population $\mathrm{S}: 66.7 \% ; \chi^{2}=2.94$, $\mathrm{df}=1, P=0.10)$.

The three groups of mating pairs differed in copulation duration (Table 2; ANOVA; $F_{2,36}=5.23, P=0.010$ ). Copulation lasted longer in $\mathrm{G} \times \mathrm{G}$ pairs than in both $\mathrm{S} \times \mathrm{S}$ and $\mathrm{G} \times \mathrm{S}$ pairs (Tukey's test: $P=0.034$ and $P=0.021$ ). Copulation duration was similar in $\mathrm{S} \times \mathrm{S}$ and $\mathrm{G} \times \mathrm{S}$ pairs $(P=0.93)$. The three groups of mating pairs did not differ in courtship latency (Table 2; Kruskal-Wallis test: $\chi^{2}=3.32, \mathrm{df}=2, P=0.19$ ) nor in courtship duration $\left(\chi^{2}=3.73, \mathrm{df}=2, P=0.16\right)$.

Breaks in mating behaviour were observed in 25 of the 39 $(64.1 \%$ ) copulating pairs (Table 2). The two homotypic groups did not differ in the percentage of pairs showing mating breaks $\left(\chi^{2}\right.$-test: $\left.\chi^{2}=0.77, \mathrm{df}=1, P=0.38\right)$. However, a higher percentage of heterotypic $\mathrm{S} \times \mathrm{G}$ pairs had breaks during mating than homotypic pairs (Table 2; all homotypic pairs combined: $\left.\chi^{2}=3.92, \mathrm{df}=1, P=0.048\right)$. Considering exclusively pairs with mating breaks, the different mating groups did not differ in number of breaks (Kruskal-Wallis test: $\chi^{2}=0.14$, df $\left.=2, P=0.93\right)$.

\section{First copulation: postcopulatory mechanism}

In the period between first and second copulation $($ mean $=$ 28.7 days, range: $7-71$ days), 20 of the $78(25.6 \%)$ focal snails deposited eggs. In both populations, the proportion of snails that produced eggs between the two copulations was not influenced by the type of mating partner (homotypic vs heterotypic; $\chi^{2}$-test, population $\mathrm{G}: \chi^{2}=0.74, \mathrm{df}=1, P=0.39$; population $\left.\mathrm{S}: \chi^{2}=0.003, \mathrm{df}=1, P=0.96\right)$. Furthermore, the number of eggs produced was not influenced by the origin of the focal snail and the type of mating partner (grand mean \pm SD: $39.4 \pm 21.0$; two-way ANOVA; population: $F_{1,16}=0.39$, $P=0.54$; mating partner: $\left.F_{1,16}=0.09, P=0.77\right)$. The time elapsed between copulation and first oviposition averaged 16.1 days (range: 7-29 days). The number of eggs produced decreased with time elapsed between copulation and first oviposition (Spearman's rank correlation: $r_{\mathrm{S}}=-0.65, n=20$, $P=0.002$ ). Two of the 20 individuals (both partners of $\mathrm{S} \times \mathrm{S}$ copulation) produced infertile eggs. In the remaining 18 snails, hatching success of eggs averaged $67.7 \%$ (range: 19.2$100.0 \%)$. Hatching success was affected neither by the origin of the focal snail nor by the type of mating partner (two-way ANOVA; population: $F_{1,14}=0.08, P=0.78$; mating partner: $\left.F_{1,14}=0.01, P=0.93\right)$. This suggests that individuals from the distant populations have maintained reproductive compatibility.

To examine whether self-fertilization occurs in offspring produced after the first mating, paternity was determined in a subsample of four families (a total of 116 hatchlings). In two of the four mothers examined a low frequency of selfing was found $(2.6 \%$ of all hatchlings): 1 hatchling out of 33 siblings $(3.0 \%)$ of one mother from population $\mathrm{S}$ and 2 out of 23 siblings $(8.7 \%)$ from one mother from population $\mathrm{G}$.

\section{Second copulation: precopulatory mechanism}

In all, 37 of the 106 (34.9\%) potential mating pairs copulated. In both populations, homotypic and heterotypic matings occurred in similar frequencies (population $\mathrm{G}: \chi^{2}=1.46, \mathrm{df}=$ $1, \quad P=0.23 ;$ population $\left.\mathrm{S}: \chi^{2}=0.04, \mathrm{df}=1, \quad P=0.83\right)$. However, the sequence of mating partners affected the proportion of successful second copulations in population G. Focal snails that copulated first with a homotypic partner remated more frequently with a homotypic partner than snails that mated first with a heterotypic partner $\left(71.4 \%\right.$ vs $27.8 \% ; \chi^{2}=$ 6.03 , df $=1, P=0.014$ ). Considering exclusively focal snails from population $\mathrm{G}$ that first mated with a homotypic partner, remating with a homotypic partner occurred more frequently $(71.4 \%)$ than with a heterotypic partner $\left(30.0 \% ; \chi^{2}=5.67\right.$,

Table 2. Duration of courtship latency, courtship and copulation in homotypic and heterotypic matings of Arianta arbustorum from two distant populations ( $\mathrm{G}$ and $\mathrm{S})$.

\begin{tabular}{|c|c|c|c|c|c|c|c|}
\hline \multirow[t]{2}{*}{ Mating pairs } & \multirow[t]{2}{*}{$m$} & \multirow[t]{2}{*}{$n$} & \multicolumn{3}{|l|}{ Duration (in min) of } & \multicolumn{2}{|c|}{ Breaks in mating behaviour } \\
\hline & & & Courtship latency & Courtship & Copulation & $\begin{array}{l}\text { Occurrence in } \\
n \text { pairs }(\%)\end{array}$ & $\begin{array}{l}\text { Mean number of breaks } \\
\text { (distribution over stages in \%) }\end{array}$ \\
\hline \multicolumn{8}{|l|}{ First mating } \\
\hline$G \times G$ & 17 & 16 & $141 \pm 107(0-440)$ & $146 \pm 102(60-500)$ & $215 \pm 84(60-320)$ & $10(62.5)$ & $1.2(8.3 ; 25.0 ; 66.7)$ \\
\hline $\mathrm{S} \times \mathrm{S}$ & 18 & 13 & $189 \pm 109(0-320)$ & $158 \pm 54(40-240)$ & $142 \pm 59(60-260)$ & $6(46.2)$ & $1.2(42.9 ; 0 ; 57.1)$ \\
\hline $\mathrm{G} \times \mathrm{S}$ & 18 & 10 & $200 \pm 155(40-560)$ & $166 \pm 62(40-240)$ & $134 \pm 63(60-220)$ & $9(90.0)$ & $1.4(46.1 ; 23.1 ; 30.8)$ \\
\hline \multicolumn{8}{|l|}{ Second mating } \\
\hline $\mathrm{G}(\times \mathrm{G}) \times \mathrm{S}$ & 14 & 6 & $173 \pm 100(40-320)$ & $160 \pm 80(80-280)$ & $210 \pm 84(60-300)$ & $3(50.0)$ & $2.0(50.0 ; 0 ; 50.0)$ \\
\hline $\mathrm{G}(\times \mathrm{S}) \times \mathrm{G}$ & 18 & 5 & $132 \pm 59(40-200)$ & $180 \pm 69(80-240)$ & $256 \pm 116(100-380)$ & $3(60.0)$ & 1.0 (33.3; 33.3; 33.3) \\
\hline $\mathrm{G}(\times \mathrm{G}) \times \mathrm{G}$ & 14 & 10 & $208 \pm 107(80-420)$ & $154 \pm 75(80-320)$ & $194 \pm 83(100-300)$ & $3(30.0)$ & $1.0(33.3 ; 0 ; 66.7)$ \\
\hline $\mathrm{S}(\times \mathrm{S}) \times \mathrm{G}$ & 20 & 5 & $268 \pm 138(140-460)$ & $208 \pm 133(100-440)$ & $140 \pm 113(60-300)$ & $3(60.0)$ & $1.3(50.0 ; 25.0 ; 25.0)$ \\
\hline$S(\times G) \times S$ & 18 & 5 & $220 \pm 94(100-300)$ & $148 \pm 58(80-220)$ & $144 \pm 95(60-280)$ & $3(60.0)$ & $1.7(60.0 ; 20.0 ; 20.0)$ \\
\hline$S(\times S) \times S$ & 18 & 6 & $187 \pm 140(0-400)$ & $130 \pm 86(40-280)$ & $163 \pm 75(60-260)$ & $0(0)$ & - \\
\hline
\end{tabular}

Snails were allowed to mate twice. Mean values \pm SD are given with ranges in parentheses; $m$ indicates the number of mating trials and $n$ the number of successful copulations. Data from both matings are shown separately. The occurrence of breaks in mating behaviour and the mean number of breaks per snail are also presented. 
REPRODUGTIVE ISOLATION IN DISTANT POPULATIONS OF ARIANTA

Table 3. Patterns of paternity in offspring of nine focal snails of Arianta arbustorum that mated twice.

\begin{tabular}{|c|c|c|c|c|c|c|c|c|c|c|}
\hline \multirow{2}{*}{$\begin{array}{l}\text { Focal snail: } \\
\text { population, } \\
\text { mother }\end{array}$} & \multicolumn{2}{|c|}{$\begin{array}{l}\text { Mating } \\
\text { sequence }\end{array}$} & \multirow{2}{*}{$\begin{array}{l}\text { Number of } \\
\text { hatchlings } \\
\text { genotyped }\end{array}$} & \multirow{2}{*}{$\begin{array}{l}\text { Number of } \\
\text { selfed } \\
\text { hatchlings }\end{array}$} & \multirow[t]{2}{*}{$P_{2}$-value } & \multicolumn{2}{|c|}{$\begin{array}{l}\text { Paternity } \\
\text { distribution }\end{array}$} & \multirow[t]{2}{*}{$\begin{array}{l}\text { Rate of } \\
\text { self-fertilization }\end{array}$} & \multirow{2}{*}{$\begin{array}{l}\text { Hatching } \\
\text { success of } \\
\text { eggs (\%) }\end{array}$} & \multirow{2}{*}{$\begin{array}{l}\text { Time elapsed } \\
\text { between } \\
\text { copulations (days) }\end{array}$} \\
\hline & First & Second & & & & $x^{2}$ & $P$ & & & \\
\hline G1 & $G$ & $\mathrm{~s}$ & 14 & 0 & 0 & 14.00 & $<0.001$ & 0 & 42.4 & 30 \\
\hline G2 & $S$ & $\mathrm{G}$ & 6 & 5 & 0 & - & - & 0.83 & 18.2 & 6 \\
\hline G3 & $S$ & $G$ & 34 & 0 & 0.94 & 26.47 & $<0.001$ & 0 & 87.2 & 6 \\
\hline G4 & $S$ & $\mathrm{G}$ & 16 & 0 & 0 & 16.00 & $<0.001$ & 0 & 47.1 & 22 \\
\hline G5 & $\mathrm{G}$ & $\mathrm{G}$ & 36 & 0 & 0.66 & 4.00 & 0.046 & 0 & 80.0 & 7 \\
\hline G6 & $G$ & $G$ & 17 & 2 & 0.33 & 1.67 & 0.20 & 0.12 & 77.3 & 33 \\
\hline G7 & $G$ & $G$ & 28 & 0 & 0.64 & 2.29 & 0.13 & 0 & 84.8 & 36 \\
\hline G8 & $\mathrm{G}$ & $\mathrm{G}$ & 44 & 0 & 0.50 & $<0.001$ & 1.00 & 0 & 91.7 & 21 \\
\hline S1 & $G$ & $S$ & 19 & 1 & 0.44 & 0.22 & 0.64 & 0.05 & 80.0 & 13 \\
\hline
\end{tabular}

Focal snails from two populations (G, Gantrisch; S, Strela) copulated with homotypic or heterotypic partners in different order. The proportion of offspring sired by the second mate is indicated by $P_{2} \cdot \chi^{2}$-tests were used to examine the null hypothesis that both partners contributed equally to the fertilization of eggs $\left(P_{1}=\right.$ $P_{2}=0.5$; in each family $\mathrm{df}=1$ ), significant $P$-values are in bold. The rate of self-fertilization, hatching success of eggs and time elapsed between the two copulations are also presented. Hatchlings from self-fertilization were excluded from the calculation of $P_{2}$-values.

$\mathrm{df}=1, P=0.017)$. Similar effects of mating partner sequence were not found in focal snails from population $\mathrm{S}$ (in all comparisons, $P>0.7$ )

The time elapsed between first and second copulation $(\bar{x}=28.7$ days $)$ differed neither between pairs of the two populations nor between homotypic and heterotypic pairs in the second mating $(n=37$, Mann-Whitney $U$-test; origin of focal snails: $z=0.15, P=0.88$; type of mating: $z=1.63, P=$ 0.10 ). However, the time elapsed between the first and second copulation was influenced by the type of mating partner in the first copulation: Focal snails from population $\mathrm{G}$ remated sooner when the first mate was a heterotypic partner than when the first mate was a homotypic partner (13.6 os 32.5 days, $n=21$, Mann-Whitney $U$-test, $z=2.40, P=0.016)$.

Independent of type of mating partner, focal snails did not differ in copulation duration, courtship latency and courtship duration (Table 2, ANOVA; copulation duration: $F_{1,35}=0.17$, $\mathrm{df}=1, P=0.68 ;$ courtship latency: $\chi^{2}=1.77, \mathrm{df}=3, P=$ 0.62; courtship duration: $\chi^{2}=1.68, \mathrm{df}=3, P=0.64$ ).

In the second copulation, breaks in mating behaviour were observed in 15 of the $37(40.5 \%)$ focal snails (Table 2). In both populations, homotypic and heterotypic copulations did not differ in number of breaks (Table $2 ; \chi^{2}=1.81$, df $=3, P=$ $0.58)$.

\section{Second copulation: postcopulatory mechanism}

Only 11 out of the 37 focal snails that mated twice laid eggs after the second copulation [8 of $21(38.1 \%)$ focal snails from population $\mathrm{G}$ and 3 of $16(18.8 \%)$ focal snails from population $\mathrm{S}]$. The sample sizes allowed only statistical comparisons in focal snails with different mating history from population $G$.

Focal snails from population $\mathrm{G}$ deposited on average 35.9 eggs (range: $22-48$ eggs, $n=8$ ). The number of eggs produced was not influenced by the mating history of the focal snail $\left(F_{2,5}=0.03, P=0.97\right)$. The hatching success of eggs, however, tended to be lower in focal snails with one heterotypic and one homotypic partner than in focal snails with two homotypic partners $(48.7 \%$ vs $84.0 \% ; t=2.35, n=8, P=0.057)$.

\section{Paternity in double-mated snails}

Paternity was analysed in a total of 214 offspring from nine focal snails that mated twice (Table 3 ). The proportions of offspring included in the paternity analysis averaged $99.1 \%$ (between-family range $95.0-100.0 \%$ ) of the total number of hatchlings produced.

The proportion of hatchlings sired by the second mating partner $\left(P_{2}\right.$-value $)$ averaged 0.39 with a range of $0-1.00(n=$ $9)$. Considering exclusively snails from population $G, P_{2}$ was 0.38 (range $0-1.00 ; n=8) . P_{2}$ was not influenced by the mating order of heterotypic and homotypic partners (Kruskal-Wallis test, $\left.\chi^{2}=2.17, \mathrm{df}=2, \quad P=0.34\right)$. Highly skewed paternity patterns were found in the progeny of four out of the nine $(44.4 \%)$ focal snails (Table 3$). P_{2}$ was not correlated with the time elapsed between the two copulations (Spearman's rank correlation, $r_{\mathrm{S}}=-0.24, n=9, P=0.54$ ). However, $P_{2}$ increased with increasing hatching success of the eggs $\left(r_{\mathrm{S}}=0.84, n=9, P=0.003\right)$.

A low frequency of self-fertilization was found in the offspring $(3.7 \%$ of all hatchlings) of three out of the nine focal snails (Table 3). Two of the three mothers with selffertilization had a heterotypic snail as a first mating partner, while the remaining mother copulated with two homotypic partners. Snails with partial self-fertilization produced fewer eggs than those with exclusive cross-fertilization (MannWhitney $U$-test, $z=2.10, n=9, P=0.036)$.

\section{DISCUSSION}

We investigated precopulatory and postcopulatory isolation mechanisms between individuals of the simultaneously hermaphroditic land snail Arianta arbustorum from two geographically distant populations. Overall, we found evidence for partial precopulatory isolation between the populations. However, paternity analyses in offspring of double-mated snails revealed that reproductive compatibility is still maintained.

In the first mating, a significant lower frequency of successful copulations was recorded in heterotypic than in homotypic pairs. A lower copulation frequency in heterotypic matings could be explained by differences in population-specific mating propensities (Fearnley, 1996). In our study, however, mating propensity did not differ between the two populations. This suggests that a partial precopulatory reproductive isolation has developed between individuals of the two distant populations.

Heterotypic pairs also showed more breaks during courtship than homotypic pairs. It has been suggested that during the long-lasting courtship with extensive reciprocal tactile and oral contacts the individuals are closely examining their potential mating partners (Leonard, 2006). Thus, individuals of 
A. arbustorum might be able to recognize differences between homotypic and heterotypic mating partners. These differences may partly be population-specific because (within a population) individuals of $A$. arbustorum mate randomly with respect to shell size and kinship (Baur, 1992; Baur \& Baur, 1997). There might be slight differences in courtship behaviour, and/ or differences in the composition of components in the snails' skin or allohormones in the mucus, i.e. substances that induce direct effects without sensory identification, and pheromones. It has been demonstrated that allohormones and pheromones influence the mating process in various invertebrate species (Koene, 2005). In Cantareus aspersus (formerly Helix aspersa), components in the mucus associated with the love dart have an effect on sperm storage and thus on the fertilization of eggs (Rogers \& Chase, 2001; Chase \& Blanchard, 2006; Chase 2007). Mate choice experiments with individuals of the closely related land snails Bradybaena pellucida and B. similaris revealed that reproductive isolation was associated with differences in sexual pheromones (Wiwegweaw et al., 2009a).

In the second mating trial, homotypic and heterotypic pairs did not differ in frequency of successful copulations or in courtship behaviour. Three different factors may explain these findings. In the first mating, virgin snails were allowed to copulate, while in the second mating the focal snails were experienced and stored sperm from the previous copulation. This might have influenced their mating behaviour (Kokko \& Mappes, 2005). In A. arbustorum one copulation is sufficient to fertilize all the eggs produced by one individual in a reproductive season (Chen \& Baur, 1993). Further matings increase the genetic variability in the offspring but are not mandatory for the fertilization of all eggs. Thus, the first mating partner should be more carefully chosen than the following partners. Alternatively, virgins might be less choosy about the first mating partner in order to begin as soon as possible with egg production in the time-limited reproductive season (Arnqvist \& Rowe, 2005).

Another explanation relates to quantity and/or quality traits of the sperm stored from the first partner. The quality and/or quantity of sperm received could influence the mating propensity and courtship behaviour in the second mating. Sperm quantity might be of minor importance because only a small fraction $(0.02-0.1 \%)$ will actually be stored in the spermatheca (Lind, 1973; Roger \& Chase, 2001). In our study, we found that snails which mated first with a heterotypic partner copulated sooner with a second partner than snails with a homotypic partner in the first copulation. This suggests that snails recognized their mating partner and assigned a heterotypic partner a lower quality than a homotypic partner. Furthermore, our finding could be explained as a consequence that homotypic partners may more effectively inhibit their partners from engaging in further matings than heterotypic partners to increase the fertilization success of their own sperm (Koene, Brouwer \& Hoffer, 2009; Koene et al., 2010).

The present study showed that snails that copulated first with a homotypic partner remated more frequently with a homotypic partner than snails which copulated first with a heterotypic partner in one of the two populations (the same effect was not found in population $\mathrm{S}$ with a smaller sample size). This indicates that previous mating encounters may influence prospective mate choice in $A$. arbustorum. Such mechanisms have already been observed in Drosophila paulistorum, where earlier mating experience with partners from the same population promoted a preference for homotypic mates (O'Hara, Pruzan \& Ehrman, 1976).

We could not find any influence of the origin of the mating partner on egg production. Thus, reproductive compatibility was still maintained as already reported in Baur \& Baur (1992a). The study design chosen (paternity analysis) did not allow us to examine the survivorship and fitness of the emerged offspring, which could be influenced by outbreeding depression (Wiwegweaw et al., 2009b). However, we recorded a reduced hatching success in eggs of focal snails which copulated with one heterotypic and one homotypic partner compared to eggs of focal snails which mated twice with homotypic partners. This may indicate a slight postcopulatory isolation between individuals of these geographically distant populations.

\section{Sperm precedence and sperm utilization}

In the present study, paternity analyses of the progeny of double-mated snails revealed no influence of the origin of the mating partner. Thus, the observed partial precopulatory reproductive isolation did not translate into sperm precedence and sperm utilization. The proportion of hatchlings sired by the second mate $\left(P_{2}\right)$ averaged 0.39 indicating a first-mate advantage. In a previous study, using shell colours as genetic markers, $P_{2}$ of double-mated individuals of $A$. arbustorum averaged 0.34 (Baur, 1994a). Nonrandom distributions and highly skewed paternity patterns in the progeny $(44.4 \%$ of the double-mated snails) could be a result of precopulatory and/or postcopulatory sexual selection, e.g. sperm competition or cryptic female choice (Birkhead \& Møller, 1998). In helicid snails, precopulatory selection processes could be due to premating behaviour like dart shooting, i.e. piercing the mating partner with a mucus-coated calcareous dart which enhances the sperm storage of the recipient (Koene \& Schulenburg, 2005; Chase, 2007). However, dart shooting is not an obligatory courtship element of $A$. arbustorum. In laboratory tests, only $50 \%$ of the copulating individuals used or tried to use the dart (Bojat \& Haase, 2002). Postcopulatory processes could be possible in $A$. arbustorum considering the morphology and complex muscular network of the sperm storage organ (spermatheca; Baur, 2007). This allows differential sperm storage and utilization (Bojat, Dürrenberger \& Haase, 2001; Bojat, Sauder \& Haase, 2001). Sperm from different fathers could be stored separately in different tubules of the spermatheca and consequently, in a further step, might be used separately for the fertilization of eggs (Haase \& Baur, 1995; Bojat \& Haase, 2002).

The skewed paternity pattern and first-mate sperm precedence recorded in the present study might be a result of sperm competition, selective storage and/or use of sperm by the focal snail. Mating order seems to be more important for the paternity pattern than the origin of the mating partner.

\section{Self-fertilization}

In simultaneous hermaphroditic pulmonate gastropods, sperm and eggs of one individual are present at the same time but stored in different storage localities (Baur, 1998). However, under certain circumstances self-fertilization may occur. In the present study, genetic analyses revealed a low frequency of selffertilization (3.7\% of all hatchlings) in the progeny of doublemated individuals of $A$. arbustorum. In a laboratory experiment, individuals of $A$. arbustorum isolated for 2-3 years produced a few self-fertilized eggs $(1-2 \%$ of the eggs of the mated snails) with low hatching success (Chen, 1994). A low frequency of self-fertilization was also recorded in one of four natural populations of $A$. arbustorum (Kupfernagel et al., 2010). However, in A. arbustorum outcrossing is preferred to self-fertilization even under outbreeding circumstances, as observed in this study. This result indicates that potential negative fitness consequences due to outbreeding depression are less costly than inbreeding depression as a result of self-fertilization (Frankham, 1995; Wiwegweaw et al., 2009b). 


\section{ACKNOWLEDGEMENTS}

We thank Anette Baur and anonymous referees for comments on the manuscript. Financial support was received from the Swiss National Science Foundation.

\section{REFERENCES}

AKÇAKAYA, H.R. \& BAUR, B. 1996. Effects of population subdivision and catastrophes on the persistence of a land snail metapopulation. Oecologia, 105: 475-483.

ARMBRUSTER, G.F.J., KOLLER, B. \& BAUR, B. 2005. Foot mucus and periostracum fraction as non-destructive sources of DNA in the land snail Arianta arbustorum, and the development of new microsatellite loci. Conservation Genetics, 6: 313-316.

ARNQVIST, G. \& ROWE, L. 2005. Sexual conflict. Princeton University Press, Princeton.

BACKelJaU, T., BAUR, A. \& BAUR, B. 2001. Population and conservation genetics. In: The biology of terrestrial molluscs (G.M. Barker, ed.), pp. 383-412. CAB International Publishing, Wallingford, UK.

BARTON, N.H. \& CHARLESWORTH, B. 1984. Genetic revolutions, founder effects, and speciation. Annual Review of Ecology and Systematics, 15: 133-164.

BAUR, B. 1984. Shell size and growth rate differences for alpine populations of Arianta arbustorum (L.) (Pulmonata: Helicidae). Revue suisse de Zoologie, 91: 37-46.

BAUR, B. 1986. Patterns of dispersion, density and dispersal in alpine populations of the land snail Arianta arbustorum (L.) (Helicidae). Holartic Ecology, 9: 117-125.

BAUR, B. 1987. The minute land snail Punctum pygmaeum (Draparnaud) can reproduce in the absence of a mate. Fournal of Molluscan Studies, 53: 112-113.

BAUR, B. 1988. Repeated mating and female fecundity in the simultaneously hermaphroditic land snail Arianta arbustorum. Invertebrate Reproduction and Development, 14: 197-204.

BAUR, B. 1990. Seasonal changes in clutch size, egg size and mode of oviposition in Arianta arbustorum (L.) (Gastropoda) from alpine populations. Zoologischer Anzeiger, 225: 253-264.

BAUR, B. 1992. Random mating by size in the simultaneously hermaphroditic land snail Arianta arbustorum: experiments and an explanation. Animal Behaviour, 43: 511-518.

BAUR, B. 1994a. Multiple paternity and individual variation in sperm precedence in the simultaneously hermaphroditic land snail Arianta arbustorum. Behavioral Ecology and Sociobiology, 35: 413-421.

BAUR, B. 1994b. Interpopulation variation in propensity for egg cannibalism in the land snail Arianta arbustorum. Animal Behaviour, 48: $851-860$.

BAUR, B. 1998. Sperm competition in molluscs. In: Sperm competition and sexual selection. (T.R. Birkhead \& A.P. Møller, eds), pp. 255-305. Academic Press, London.

BAUR, B. 2007. Reproductive biology and mating conflict in the simultaneously hermaphroditic land snail Arianta arbustorum. American Malacological Bulletin, 23: 157-172.

BAUR, B. \& BAUR, A. 1992a. Reduced reproductive compatibility in Arianta arbustorum (Gastropoda) from distant populations. Heredity, 69: $65-72$.

BAUR, B. \& BAUR, A. 1992b. Effect of courtship and repeated copulation on egg production in the simultaneously hermaphroditic land snail Arianta arbustorum. Invertebrate Reproduction and Development, 21: $201-206$.

BAUR, B. \& BAUR, A. 1997. Random mating with respect to relatedness in the simultaneously hermaphroditic land snail Arianta arbustorum. Invertebrate Biology, 116: 294-298.

BAUR, B. \& GOSTELI, M. 1986. Between and within population differences in geotactic response in the land snail Arianta arbustorum (L.) (Helicidae). Behaviour, 97: 147-160.

BAUR, B. \& RABOUD, C. 1988. Life history of the land snail Arianta arbustorum along an altitudinal gradient. Fournal of Animal Ecology, 57: $71-87$.
BEESE, K., ARMBRUSTER, G.F.J., BEIER, K. \& BAUR, B. 2009. Evolution of female sperm storage organs in the carrefour of stylommatophoran gastropods. Fournal of Zoological Systematics and Evolutionary Research, 47: 49-60.

BEESE, K., BEIER, K. \& BAUR, B. 2006. Bursa tract diverticulum in the hermaphroditic land snail Arianta arbustorum (Stylommatophora: Helicidae): Morphology, function, and evolutionary implications. Fournal of Morphology, 267: 940-953.

BIRKHEAD, T.R. \& MØLLER, A.P. (Eds). 1998. Sperm competition and sexual selection. Academic Press, London.

BOJAT, N.G., DÜRRENBERGER, M. \& HAASE, M. 2001. The spermatheca in the land snail, Arianta arbustorum (Pulmonata: Stylommatophora): Muscle system and potential role in sexual selection. Invertebrate Biology, 120: 217-226.

BOJAT, N.G. \& HAASE, M. 2002. Sperm storage in the simultaneously hermaphroditic land snail, Arianta arbustorum. Fournal of Zoology, 258: 497-503.

BOJAT, N.G., SAUDER, U. \& HAASE, M. 2001. The spermathecal epithelium, sperm and their interactions in the hermaphroditic land snail Arianta arbustorum (Pulmonata, Stylommatophora). Zoomorphology, 120: 149-157.

CAIN, A.J. \& CURREY, J.D. 1968. Studies on Cepaea. III. Ecogenetics of a population of Cepaea nemoralis (L.) subject to strong area effects. Philosophical Transactions of the Royal Society B: Biological Sciences, 253: 447-482.

CHASE, R. 2007. The function of dart shooting in helicid snails. American Malacological Bulletin, 23: 183-189.

CHASE, R. \& BLANCHARD, K.C. 2006. The snail's love-dart delivers mucus to increase paternity. Proceedings of the Royal Society Series B, 273: $1471-1475$.

CHASE, R. \& DARBYSON, E. 2008. Differential survival of allosperm by location within the female storage organ of the snail Cornu aspersum (Müller, 1774). Canadian Fournal of Zoology, 86: $1244-1251$.

CHEN, X. 1994. Self-fertilization and cross-fertilization in the land snail Arianta arbustorum (Mollusca, Pulmonata: Helicidae). Fournal of Zoology, 232: 465-471.

CHEN, X. \& BAUR, B. 1993. The effect of multiple mating on female reproductive success in the simultaneously hermaphroditic land snail Arianta arbustorum. Canadian Fournal of Zoology, 71: 2431-2436.

COYNE, J.A. \& ORR, H.A. 2004. Speciation. Sinauer Associates Inc., Sunderland, Massachusetts.

DAKIN, E.E. \& AVISE, J.C. 2004. Microsatellite null alleles in parentage analysis. Heredity, 93: 504-509.

FEARNLEY, R.H. 1996. Heterogenic copulatory behaviour produces non-random mating in laboratory trials in the land snail Helix aspersa Müller. Fournal of Molluscan Studies, 62: 159-164.

FRANKHAM, R. 1995. Inbreeding and extinction - a threshold effect. Conservation Biology, 4: 792-799.

GITTENBERGER, E. 1988. Sympatric speciation in snails; a largely neglected model. Evolution, 4: 826-828.

GOODWILlie, C., KALISZ, S. \& EGKERT, G.G. 2005. The evolutionary enigma of mixed mating systems in plants: occurrence, theoretical explanations and empirical evidence. Annual Review of Ecology and Systematics, 36: 47-79.

GREEFF, J.M. \& MICHIELS, N.K. 1999. Low potential for sexual selection in simultaneously hermaphroditic animals. Proceedings of the Royal Society of London, Series B, 266: 1671-1676.

HAASE, M. \& BAUR, B. 1995. Variation in spermathecal morphology and storage of spermatozoa in the simultaneously hermaphroditic land snail Arianta arbustorum. Invertebrate Reproduction and Development, 28: $33-41$.

HÄNGGI, C., LOCHER, R. \& BAUR, B. 2002. Intermating interval and number of sperm delivered in the simultaneously hermaphroditic land snail Arianta arbustorum (Pulmonata: Helicidae). Veliger, 45: 224-230.

HANSKI, I.A. \& GILPIN, M.E. 1997. Metapopulation biology: ecology, genetics and evolution. Academic Press, New York.

HELLER, J. 1993. Hermaphroditism in molluscs. Biological fournal of the Linnean Society, 48: 19-42. 


\section{S. KUPFERNAGEL AND B. BAUR}

HOFMANN, E. 1923. Über den Begattungsvorgang von Arianta arbustorum (L.). Fenaische Zeitschrift der Naturwissenschaften, $\mathbf{5 9}$ : $363-400$.

JARNE, P. \& AULD, J.R. 2006. Animals mix it up too: the distribution of self-fertilization among hermaphroditic animals. Evolution, 60: 1816-1824.

KERNEY, M.P. \& CAMERON, R.A.D. 1979. A field guide to the land snails of Britain and north-west Europe. Collins, London.

KOENE, J.M. 2005. Allohormones and sensory traps: a fundamental difference between hermaphrodites and gonochorists? Invertebrate Reproduction and Development, 48: 101-107.

KOENE, J.M., BROUWER, A. \& HOFFER, J.N.A. 2009. Reduced egg laying caused by a male accessory gland product opens the possibility for sexual conflict in a simultaneous hermaphrodite. Animal Biology, 59: 435-448.

KOENE, J.M. \& SCHULENBURG, H. 2005. Shooting darts: co-evolution and counter-adaptation in hermaphroditic snails. $B M C$ Evolutionary Biology, 5: 25-38.

KOENE, J.M., SLOOT, W., MONTAGNE-WAJER, K., CUMmins, S.F., DEGNAN, B.M., SMITH, J.S., NAGLE, G.T. \& TER MAAT, A. 2010. Male accessory gland protein reduces egg laying in a simultaneous hermaphrodite. PLoS One, 5: e10117.

KOKKO, H. \& MAPPES, J. 2005. Sexual selection when fertilization is not guaranteed. Evolution, 59: 1876-1885.

KUPFERNAGEL, S., RUSTERHOLZ, H.P. \& BAUR, B. 2010. Variation in multiple paternity and sperm utilization patterns in natural populations of a simultaneous hermaphrodite land snail. Biological Fournal of the Linnean Society, 99: 350-361.

LANDE, R. \& SCHEMSKE, D.W. 1985. The evolution of self-fertilization and inbreeding depression in plants. I. Genetic models. Evolution, 39: 24-40.

LEONARD, J.L. 2006. Sexual selection: lessons from hermaphrodite mating systems. Integrative and Comparative Biology, 46: 349-367.

LEVINS, R. 1968. Evolution in changing environments. University Press, Princeton.

LIND, H. 1973. The functional significance of the spermatophore and the fate of spermatozoa in the genital tract of Helix pomatia (Gastropoda: Stylommatophora). Fournal of Zoology, 168: 39-64.

LOCHER, R. \& BAUR, B. 1999. Effects of intermating interval on spermatophore size and sperm number in the simultaneously hermaphroditic land snail Arianta arbustorum. Ethology, 105: 839-849.

McCARTHY, T.M. \& SIH, A. 2008. Relatedness of mates influences mating behaviour and reproductive success of the hermaphroditic freshwater snail Physa gyrina. Evolutionary Ecology Research, 10: 77-94.

MAYR, E. 1963. Animal species and evolution. Harvard University Press, Cambridge, Massachusetts.

O'HARA, E., PRUZAN, A. \& EHRMAN, L. 1976. Ethological isolation and mating experience in Drosophila paulistorum. Proceedings of the National Academy of Sciences of the USA, 73: 975-976.

PEMBERTON, J.M., SLATE, J., BRANCROFT, D.R. \& BARRETT, J.A. 1995. Nonamplifying alleles at microsatellite loci: a caution for parentage and population studies. Molecular Ecology, 4: $249-252$.

QIAGEN. 2003. QIAGEN ${ }^{\circledR}$ multiplex PCR handbook. Qiagen Inc., Switzerland.

QIAGEN. 2006. Dneasy ${ }^{\circledR}$ blood $\&^{\circ}$ tissue handbook. Qiagen Inc., Switzerland.

ROGERS, D.W. \& CHASE, R. 2001. Dart receipt promotes sperm storage in the garden snail Helix aspersa. Behavioral Ecology and Sociobiology, 50: 122-127.

RUNDLE, H.D. \& NOSIL, P. 2005. Ecological speciation. Ecology Letters, 8: 336-352.

SCHILTHUIZEN, M., VAN TIL, A., SALVERDA, M., LIEW, T.S., SHEENA, J.S., BIN ELAHAN, B. \& VERMEULEN, J.J. 2006. Microgeographic evolution of snail shell shape and predator behavior. Evolution, 60: 1851-1858.

SPSS. 2006. SPSS ${ }^{\circledR}$ 13. SPSS Inc., Chigaco.

WIWEGWEAW, A., SEKI, K., MORI, H. \& ASAMI, T. 2009a. Asymmetric reproductive isolation during simultaneous reciprocal mating in pulmonates. Biology Letters, 5: 240-243.

WIWEGWEAW, A., SEKI, K., UTSUNO, H. \& ASAMI, T. 2009b. Fitness consequences of reciprocally asymmetric hybridization between simultaneous hermaphrodites. Zoological Science, 26: $191-196$.

WOLDA, H. \& KREULEN, D.A. 1973. Ecology of some experimental populations of the land snail Cepaea nemoralis (L.) II. Production and survival of eggs and juveniles. Netherlands Fournal of Zoology, 23: 168-188. 